\author{
J Daniel Diaz ${ }^{1,3}$, Jorge L Bustillo' \\ Idarmes C Pacheco ${ }^{2}$ and David C \\ $\mathrm{Gritz}^{3,4}$ \\ ${ }^{1}$ Massachusetts Eye and Ear Infirmary, Harvard \\ Medical School, Boston, Massachusetts, USA \\ ${ }^{2}$ Instituto Superior de Ciencias Medicas de Sancti \\ Spiritus, Cuba \\ ${ }^{3}$ Albert Einstein College of Medicine, Department of \\ Ophthalmology, Montefiore Medical Center, Bronx, \\ New York, USA \\ ${ }^{4}$ King Khaled Eye Specialist Hospital, Riyadh, Saudi \\ Arabia
}

Dates: Received: 13 Oct, 2016; Accepted: 24 Oct, 2016; Published: 25 Oct, 2016

*Corresponding author: Jose Daniel Diaz, MD, 221 Newbury St, STE 3F, Boston, MA, 02116, USA, Tel: 305-794-6117; E-mail: jdiazmd1@gmail.com

www.peertechz.com

ISSN: 2455-1414

Keywords: Epidemiology; International ophthalmology; Ocular toxoplasmosis; Posterior uveitis

\section{Research Article \\ Cuban Ocular Toxoplasmosis Epidemiology Study (COTES): Clinical Features in 279 Patients from Central Cuba}

\section{Introduction}

Toxoplasma gondii, an obligate intracellular protozoan with a broad range of hosts, continues to be the most common cause of infectious posterior uveitis in humans [1]. Cats are the definitive hosts for T. gondii, and humans and other mammals continue to act as intermediate hosts. The transmission occurs by many routes, including ingestion of raw or undercooked meat infected with tissue cysts, ingestion of food and water contaminated with oocysts, ingestion of eggs and milk contaminated with tachyzoites, blood transfusion, organ transplantation, and even transplacental transmission $[1,2]$. Interestingly, visual symptoms during acute toxoplasma retinochoroiditis are typically secondary to vitritis. Vision loss may become permanent due to formation of a macular scar or the presence of optic atrophy. Although the classic tripledrug therapy of pyrimethamine, sulfadiazine, and corticosteroid is an effective choice, alternative treatment regimens including single agent treatment with trimethoprim-sulfamethoxazole, intravitreal injection of clindamycin with dexamethasone, or combination of azithromycin with pyrimethamine have been shown to be effective against ocular toxoplasmosis [1-3].

Despite its worldwide prevalence, worldwide rates of ocular toxoplasmosis (OT) infection differ, with under-developed countries having higher rates of infection. The prevalence of OT has been reported to be higher in tropical regions, with seroepidemiological research examining OT in Brazil and Colombia showing that there is an increased prevalence in South America, Central America, and the Caribbean compared to North America and Europe [1-3].
Although demographics and clinical manifestations of OT have been extensively described in large parts of the world, there continues to be a lack of characterization of OT in the Caribbean. The aim of this non-comparative case series is to describe the clinical features and demographics of OT in patients evaluated at a large tertiary referral center in previously unassessed Central Cuba.

\section{Materials and Methods}

A retrospective study of the medical records of patients seen and evaluated at the Centro Oftalmológico Provincial hospital in Sancti Spiritus, Central Cuba was performed. The Centro Oftalmológico Provincial hospital, opened in 2007, is a large tertiary referral center that serves patients in a catchment area spanning over 20 municipalities (in 5 provinces) in Central Cuba. The majority of patients are seen from within the Sancti Spiritus province, which is made up of eight municipalities (Figure 1). A prospective database kept by physicians at the center was used to identify all patients coded with the diagnosis of OT during a consecutive 24-month period from April 1, 2011, through March 31, 2013. Medical records were reviewed to confirm inclusion criteria and gather demographic and clinical data.

All patients presenting with a diagnosis of OT during the study period were included in the cohort. Patients were categorized according to acquisition of the infection (acquired or congenital). Patients known to be HIV positive were not on antiretroviral medications at the time of diagnosis with OT and were subdivided for comparison against immunocompetent patients. 


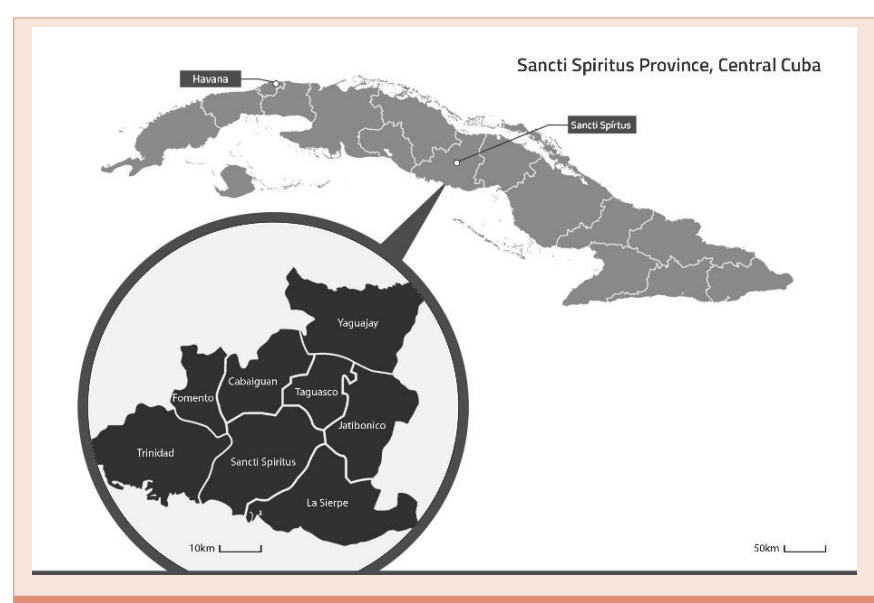

Figure 1: Map of Cuba showing the location of the Sancti Spiritus Province and its corresponding municipalities. (see attached).

Only patients with definitive clinical diagnoses were included in the study. Clinical diagnosis of acquired OT was defined by the presence of classic active focal retinochoroidal inflammation without associated retinochoroidal scars in either eye as well as a response to therapy as expected. Furthermore, these patients had no history of prior documented episodes or symptoms suggestive of prior episodes. A diagnosis of congenital OT was made based on multiple factors including: the presence of quiescent retinal toxoplasmic scars before the age of seven years, complications, and retinochoroidal lesions in the mother. Because of the presence of old scars in some patients, the exact time of onset of ocular disease who could not be determined and these patients were classified as undetermined.

Data gathered during the evaluation included demographics (gender, race, age at presentation, location of residence); clinical features (slit lamp findings of anterior and posterior segments, and visual acuity recorded in decimal form); therapeutic treatment and duration; complications; and other pertinent clinical information (i.e. immune status). These clinical variables were compared across the various groups. Self-identification was used to collect an individual's data on race, which was categorized into white (of European descent) or non-white (mixed-race, Black, and Asian). The categorization into white and non-white is a common cultural designation in Cuba.

Initial best-corrected visual acuity was determined on presentation. Visual acuity data was categorized as a slight decrease (0.9-0.6), a moderate decrease (0.5-0.2), or a large decrease $(<0.1)$.

The zone of retinochoroiditis involved was determined by using indirect ophthalmoscopy. Holland described the technique of localizing infectious retinitis lesions to one or more of 3 retinal zones in 1989 [4]. As defined in the original study, zone 1 corresponds to an area comprising both 2 disc diameters $(3600 \mathrm{um}$ ) from the foveal center and 1 disc diameter (1800 um) from the margins of the optic disc. Lesions localized to this area are considered to be the most sightthreatening. Zone 2 is defined as the area extending from zone 1 to the clinical equator of the eye; identified by the anterior borders of the ampullae of the vortex veins; and zone 3 extends from the equator to the ora serrata.
Statistical analysis was performed using the Stata statistical software program (STATA Corp., College Station, TX). The Pearson chi-squared test and Fisher's exact test was used as indicated by the data. The Student's t-test was used in the comparison of means and $\mathrm{p}$ values $<0.05$ were considered statistically significant.

This study was reviewed and approved by the Institutional Review Board of Montefiore Medical Center and Albert Einstein College of Medicine and by the Centro Oftalmológico Provincial Hospital. All procedures followed adherence to the tenets of the Declaration of Helsinki and HIPPA regulations. The identities of patients were kept confidential. No informed consent was required for this study.

\section{Results}

\section{Study population characteristics}

In total, 279 patients from five provinces (20 municipalities) across Central Cuba fulfilled the inclusion criteria. Patient demographic and ophthalmic data is given in Table 1. Ages ranged from 1 to 84 years (mean age, 35.2; median age, 36 years). Overall, $67 \%(n=186)$ of the cohort was diagnosed with acquired OT (44.6\% male, $55.4 \%$ female) with a mean age of 35.4 and $1.8 \%(n=5)$ was congenital $(80 \%$ male, $20 \%$ female) with a mean age of $3.4(\mathrm{p}=0.179$ and $<0.0001$ for gender and age comparisons, respectively). Three of the five patients with congenital OT presented with quiescent retinochoroidal scars before the age of seven years, and two patients presented with active retinochoroidal lesions before two years of age. Five percent $(n=13)$ acquired OT during pregnancy with a mean age of 25.4 and $3.2 \%$ $(n=9)$ of patients were HIV positive at the time of diagnosis with a mean age of 46.1. Mean follow-up was 8 months (range, 2-30 months). No patients were receiving immunosuppressive medications at the time of first presentation with OT and, other than HIV, there were no other reasons for immunosuppression.

The time of onset for the T. gondii infection could not be accurately determined in $28 \%(n=79)$ of patients, often due to the presence of quiescent subclinical retinochoroidal scarring, which was noted in $60 \%(n=45)$ of these patients. In total, 329 affected eyes in 279 patients were documented, with unilateral disease noted in $82.1 \%$ $(n=229)$ of all patients. There was no significant difference in bilateral versus unilateral disease between acquired and congenital groups or between acquired HIV positive and negative patients ( $\mathrm{p}=1.000$ and 0.215 , respectively). Overall, $65.6 \%(n=183)$ of all patients were aged between 15 and 45 years (Figure 2). Of these patients, 83.1\% ( $\mathrm{n}=152)$ presented with symptomatic active OT.

\section{Clinical manifestations and visual acuity}

Table 2 details the clinical manifestations found in patients with OT. Classic active retinochoroidal lesions were noted upon initial presentation in $72.8 \%(\mathrm{n}=203)$ of patients while quiescent retinal scars were noted in $16.1 \%(n=45)$ of patients. HIV positive patients with acquired OT were more likely to present with multifocal retinochoroidal lesions than HIV negative patients $(\mathrm{p}<0.001)$. Three patients with active retinochoroidal lesions presented with concomitant optic nerve involvement (Jensen's disease). Kyrieleis arteritis, manifested by nodular yellow plaques within retinal arteries, was noted in three patients. 
Of the total 279 patients, $86 \% \quad(n=240)$ presented with either a moderate or large decrease in visual acuity (Table 2). Furthermore, HIV positive patients with acquired OT were more likely to experience a large decrease in visual acuity compared to immunocompetent patients $(\mathrm{p}=0.039)$. Patients who presented with clinical manifestations of panuveitis, multifocal active retinochoroidal lesions, and multifocal choroiditis were more likely to experience a large decrease in visual acuity $(\mathrm{p}<0.001, \mathrm{p}<0.001$, and $\mathrm{p}=0.005$, respectively). In contrast, patients presenting with quiescent retinochoroidal scars had less severe decreases in visual acuity $(\mathrm{p}<0.001)$

\section{Retinal lesions}

The zonal location of retinal lesions in all affected eyes of patients

\begin{tabular}{|c|c|c|c|c|}
\hline \multicolumn{5}{|c|}{ Diagnosis } \\
\hline & $\begin{array}{l}\text { Congenital } \\
\text { Ocular } \\
\text { Toxoplasmosis }\end{array}$ & $\begin{array}{l}\text { Acquired } \\
\text { Ocular } \\
\text { Toxoplasmosis }\end{array}$ & $\begin{array}{l}\text { Acquired Ocular } \\
\text { Toxoplasmosis } \\
\text { in HIV patients }\end{array}$ & Undetermined \\
\hline & $N(\%)$ & $N(\%)$ & $N(\%)$ & $N(\%)$ \\
\hline Total $(\mathrm{N}=279)$ & $5(1.8)$ & $186(66.7)$ & $9(3.2)$ & 79 (28.3) \\
\hline \multicolumn{5}{|l|}{ Sex } \\
\hline Male & $4(80.0)$ & $83(44.6)$ & $5(55.6)$ & $20(25.3)$ \\
\hline Female & $1(20.0)$ & $103(55.4)$ & $4(44.4)$ & $59(74.7)$ \\
\hline \multicolumn{5}{|l|}{ Race } \\
\hline White & $5(100)$ & $126(67.7)$ & $6(66.7)$ & 47 (59.5) \\
\hline Non-white & $0(0)$ & $60(32.3)$ & $3(33.3)$ & $32(40.5)$ \\
\hline $\begin{array}{l}\text { Median age, y } \\
\text { (range) }\end{array}$ & $3.4(1-6)$ & $35.4(5-80)$ & $46.1(35-72)$ & $35.7(5-84)$ \\
\hline \multicolumn{5}{|l|}{$\begin{array}{l}\text { Affected Eye } \\
(\mathrm{N}=329)\end{array}$} \\
\hline Right & $2(40.0)$ & $87(46.8)$ & $5(55.6)$ & 25 (31.6) \\
\hline Left & $2(40.0)$ & 63 (33.9) & $4(44.4)$ & $41(51.9)$ \\
\hline Bilateral & $1(20.0)$ & $36(19.4)$ & $0(0)$ & $13(16.5)$ \\
\hline
\end{tabular}

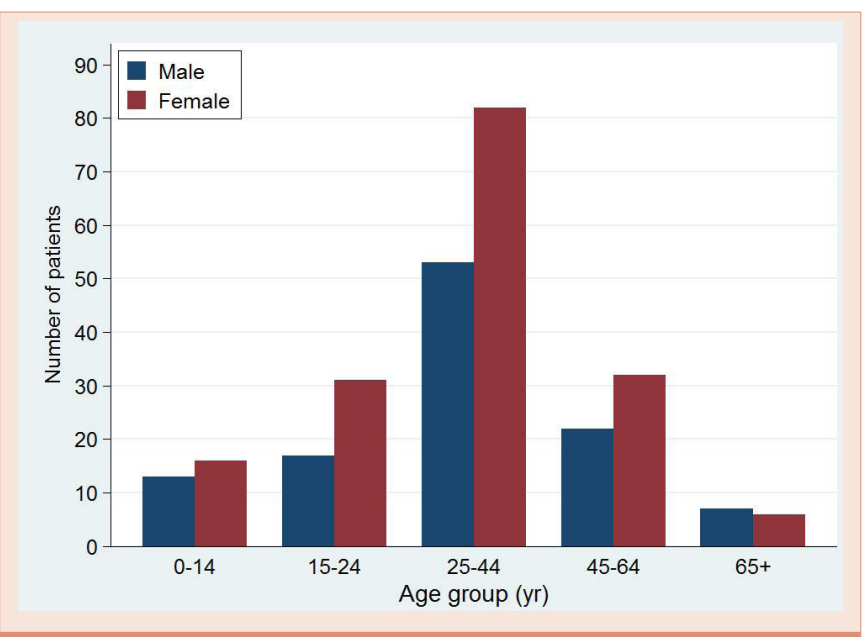

Figure 2: Number of patients with ocular toxoplasmosis, stratified by age and gender. who presented with active OT is summarized in Table 3. Of the total 271 eyes affected with active OT, $37.3 \%(n=101)$ had lesions that were located within zone 1 , nearest to the macula and optic nerve. Sixteen percent $(\mathrm{n}=44)$ had lesions spanning zones 1 and 2 and $35.4 \%(\mathrm{n}=96)$ had lesions solely within zone 2 , while more peripheral lesions in zone 3 were observed in $11.1 \%(n=30)$ of affected eyes. Patients with congenital OT were more likely to contain central lesions in zone 1 compared to patients with acquired OT $(\mathrm{p}=0.011)$.

\section{Complications}

Complications developed in $42.3 \%$ ( $n=118)$ of patients. The most common complications included strabismus $(9.7 \%, \mathrm{n}=27)$, epiretinal membranes $(7.5 \%, \mathrm{n}=21)$, glaucoma $(5.4 \%, \mathrm{n}=15)$, and cataract $(5.0 \%$, $\mathrm{n}=14$ ) (Table 4). Strabismus developed more often in patients with congenital OT compared to patients with acquired OT ( $p<0.001)$. All retinal lesions noted in patients with strabismus were localized to zone 1. Neurotoxoplasmosis and optic nerve atrophy was observed more often in HIV positive patients with acquired OT compared to immunocompetent patients with acquired OT $(\mathrm{p}<0.001$ in both cases). No difference in the development of complications was observed between treated and untreated patients.

\section{Treatment}

Treatment data is shown in Table 5. In total, $83.5 \%(n=233)$ of patients were treated for OT. Forty percent $(n=112)$ received the antiparasitic agents pyrimethamine and sulfadiazine along with oral corticosteroids, $27.2 \%(n=76)$ received sulfamethoxazole (SMX) with oral corticosteroids, and $16.1 \%(n=45)$ were treated with a combination of trimethoprim (TMP), SMX, azithromycin, and oral corticosteroids. Treatment for immunocompetent patients with acquired OT varied, with $38.2 \%(n=71)$ of these patients treated with antiparasitic agents, $37.6 \%(n=70)$ treated with SMX and oral corticosteroids, and $24.2 \%(\mathrm{n}=45)$ treated with TMP-SMX, azithromycin and oral corticosteroids.

\section{Discussion}

This study examined the demographics and clinical features of a large cohort of patients with OT over a 24-month study period in Central Cuba. Sixty-seven percent of patients were diagnosed with acquired OT and $1.8 \%$ were congenital. Over $80 \%$ of patients presented with signs of active symptomatic OT, with those presenting with retinal lesions in zone 1 more likely to experience moderate or large decreases in visual acuity. On average, HIV positive patients presented more often with signs of advanced toxoplasmosis, such as multifocal retinal lesions and the development of intracranial toxoplasmosis (Table 4).

The mean age at initial presentation for patients with active OT was 35.6 , slightly higher than previous reports [1,5-8]. Overall, $60 \%$ of all patients were aged between 10 and 40 , consistent with the observation that OT manifests most commonly during the second through fourth decades of life [5,6,9-11]. Unilateral ocular involvement was present in $82 \%$ of all patients, similar to previous reports $[6,12]$.

This report supports recent evidence which suggests that more people are affected by postnatal rather than by prenatal 


\begin{tabular}{|c|c|c|c|c|c|c|}
\hline \multicolumn{2}{|l|}{ Total } & \multicolumn{5}{|c|}{ Diagnosis } \\
\hline & $\begin{array}{l}N=279 \text { patients } \\
N(\%)\end{array}$ & $\begin{array}{l}\text { 1.Congenital Ocular } \\
\text { Toxoplasmosis } \\
N=5 \\
N(\%)\end{array}$ & $\begin{array}{l}\quad \text { 2.Acquired Ocular } \\
\text { Toxoplasmosis } \\
N=186 \\
N(\%)\end{array}$ & $\begin{array}{l}1 \text { vs. } 2 \\
P \text { Value }\end{array}$ & $\begin{array}{l}\text { 3.Acquired Ocular Toxoplasmosis in } \\
\text { HIV patients } \\
N=9 \\
N(\%)\end{array}$ & $\begin{array}{l}2 \text { vs. } 3 \\
\text { PValue }\end{array}$ \\
\hline \multicolumn{7}{|l|}{ Manifestation } \\
\hline $\begin{array}{l}\text { Quiescent focal } \\
\text { retinochoroiditis }\end{array}$ & $45(16.1)$ & $3(60)$ & $0(0)$ & $<0.001$ & $0(0)$ & \\
\hline Panuveitis & $31(11.1)$ & $0(0)$ & $0(0)$ & & $0(0)$ & \\
\hline \multicolumn{7}{|l|}{ Visual Acuity } \\
\hline Slight decrease (0.9-0.6) & $39(14.0)$ & $0(0) v$ & $14(7.5)$ & 1.000 & $0(0)$ & 1.000 \\
\hline $\begin{array}{l}\text { Moderate decrease (0.5- } \\
0.2 \text { ) }\end{array}$ & $124(44.4)$ & $3(60)$ & $96(51.6)$ & 1.000 & $2(22.2)$ & 0.100 \\
\hline Large decrease $(<0.1)$ & $116(41.6)$ & $2(40)$ & $76(40.9)$ & 1.000 & 7 (77.8) & 0.039 \\
\hline
\end{tabular}

Table 3: Retinal Lesion and Visual Acuity Characteristics in Patients Presenting with Active Ocular Toxoplasmosis.

\begin{tabular}{|l|l|l|l|l|l|}
\hline \multicolumn{5}{|c|}{ Location of Retinal Lesions } \\
\hline & Zone 1 & $\begin{array}{l}\text { Zone } \\
1+2\end{array}$ & Zone 2 & Zone 3 \\
\hline & $N(\%)$ & $N(\%)$ & $N(\%)$ & $N(\%)$ \\
\hline Total $(\mathrm{N}=271$ affected eyes $)$ & $\begin{array}{l}101 \\
(37.3)\end{array}$ & $\begin{array}{l}44 \\
(16.2)\end{array}$ & $\begin{array}{l}96 \\
(35.4)\end{array}$ & $\begin{array}{l}30 \\
(11.1)\end{array}$ \\
\hline Diagnosis & & & & \\
\hline Congenital ocular toxoplasmosis $(\mathrm{n}=2)$ & $2(100)$ & $0(0)$ & $0(0)$ & $0(0)$ \\
\hline Acquired ocular toxoplasmosis $(\mathrm{n}=222)$ & $79(35.6)$ & $\begin{array}{l}34 \\
(15.3)\end{array}$ & $\begin{array}{l}85 \\
(38.3)\end{array}$ & $\begin{array}{l}24 \\
(10.8)\end{array}$ \\
\hline $\begin{array}{c}\text { Acquired ocular toxoplasmosis in HIV } \\
\text { patients }(\mathrm{n}=9)\end{array}$ & $2(22.2)$ & $1(11.1)$ & $6(66.7)$ & $0(0)$ \\
\hline Undetermined $(\mathrm{n}=38)$ & $18(47.4)$ & $9(23.7)$ & $5(13.1)$ & $6(15.8)$ \\
\hline Visual Acuity & & & & \\
\hline Slight decrease $(0.9-0.6)(\mathrm{n}=19)$ & $6(31.6)$ & $0(0)$ & $7(36.8)$ & $6(31.6)$ \\
\hline Moderate decrease $(0.5-0.2)(\mathrm{n}=125)$ & $49(39.2)$ & $1(0.8)$ & $\begin{array}{l}68 \\
(54.4)\end{array}$ & $7(5.6)$ \\
\hline Large decrease $(<0.1)(\mathrm{n}=127)$ & $46(36.2)$ & $\begin{array}{l}43 \\
(33.9)\end{array}$ & $\begin{array}{l}21 \\
(16.5)\end{array}$ & $\begin{array}{l}17 \\
(13.4)\end{array}$ \\
\hline
\end{tabular}

toxoplasmosis [9,13-16]. The presence of quiescent retinochoroidal scars on initial presentation in $16.1 \%(n=45)$ of patients prevented the determination of the exact age and mode of acquisition of OT in this group. Subsequently, this undetermined group was not compared to the acquired or congenital group at the risk of overestimating or underestimating possible differences.

T. gondii retinal lesion location has been shown to have an effect on visual acuity in patients $[5,8,17]$. Recently, in a prospective study of 281 children with congenital toxoplasmosis, Tan et al., observed that nearly half the children with a posterior pole lesion developed a visual impairment in the affected eye, compared to less than $20 \%$ of those with more peripheral lesions [17]. Additionally, Bosch-Driessen et al., attributed legal blindness in nearly one quarter of 154 patients to the macular location of retinal lesions and retinal detachments [5]. In this study, utilizing retinal zone definitions described by Holland et al. [4], 37.3\% of active lesions were localized to zone 1. Lesions located within zone 1 and those involving both zones 1 and 2 were associated with larger decreases in visual acuity than more peripheral lesions ( $\mathrm{p}=0.001$, Table 3$)$.

Furthermore, the zonal location of retinal lesions was associated with the presence or development of strabismus. Patients who developed strabismus were more likely to have a lesion localized to zone 1 ( $\mathrm{p}<0.001)$. The proximity of the lesion to the macula and optic nerve and subsequent sensory deprivation in the affected eye, if untreated for extended periods, is likely to accelerate the development of strabismus. Strabismus was present or developed in $25 \%(n=11)$ of pediatric patients during the study period. This finding is especially important in young children, who are often unable to vocalize a decrease in vision, and is a likely reason why strabismus has been described more often in this population. In a study investigating long term OT involvement in patients with congenital OT, Meenken et al., reported the occurrence of strabismus in $76 \%$ of patients [18]. Additionally, Kodjikian et al., in France attributed the development of strabismus to the macular location of lesions in $86 \%$ of cases [19]. A number of studies have reported similar observations, with the development of strabismus in pediatric patients ranging from $36 \%$ to $70 \%[20,21]$.

The risks of advanced or disseminated toxoplasmosis in immunocompromised hosts are well known, and several studies have reported on the benefits of earlier and continued treatment in this group of patients [22-24]. In the present study, HIV positive patients with acquired OT more often presented with multifocal active retinal lesions compared to immunocompetent patients. $(\mathrm{p}<$ 0.001 ). Decreased immune system responses in immunosuppressed or immunodeficient patients may facilitate an increased parasitic load, leading to the development of additional lesions [23,25,26]. This is further supported by Bosch-Driessen et al., who reported that multifocal retinal disease was more common in patients that were immunosuppressed and treated solely with corticosteroids [5].

Various atypical manifestations of ocular toxoplasmosis have been previously described and were noted here in several patients. Kyrieleis arteritis, a type of retinal vasculitis with segmental yellow-white intra-arterial plaques was observed in three patients. All presented 
Table 4: Complications in Patients with Ocular Toxoplasmosis.

\begin{tabular}{|c|c|c|c|c|c|c|}
\hline & \multirow[b]{2}{*}{ Total } & \multicolumn{4}{|c|}{ Diagnosis } & \multirow[b]{3}{*}{$\begin{array}{l}2 \text { vs. } 3 \\
P \text { Value }\end{array}$} \\
\hline & & \multirow{2}{*}{$\begin{array}{l}\text { 1. Congenital Ocular } \\
\text { Toxoplasmosis } \\
\begin{array}{l}N=5 \\
N(\%)\end{array}\end{array}$} & \multirow{2}{*}{$\begin{array}{l}\text { 2. Acquired Ocular } \\
\text { Toxoplasmosis } \\
\begin{array}{l}N=186 \\
N(\%)\end{array}\end{array}$} & \multirow[b]{2}{*}{$\begin{array}{l}1 \text { vs. } 2 \\
P \text { Value }\end{array}$} & $\begin{array}{l}\text { 3. Acquired Ocular } \\
\text { Toxoplasmosis in HIV } \\
\text { patients }\end{array}$ & \\
\hline & $\begin{array}{l}N=279 \text { patients } \\
N(\%)\end{array}$ & & & & $N=9 \quad N(\%)$ & \\
\hline Strabismus & $27(9.7)$ & $3(60)$ & $2(1.1)$ & $<0.001$ & $0(0)$ & \\
\hline Glaucoma & $15(5.4)$ & $0(0)$ & $11(5.9)$ & 1.000 & $0(0)$ & \\
\hline Cataract & $14(5.0)$ & $0(0)$ & $8(4.3)$ & 1.000 & $0(0)$ & \\
\hline Macular hole & $7(2.5)$ & $0(0)$ & $3(1.6)$ & 1.000 & $0(0)$ & \\
\hline CNV & $6(2.2)$ & $1(20)$ & $4(2.2)$ & 0.125 & $0(0)$ & \\
\hline Neurotoxoplasmosis & $6(2.2)$ & $0(0)$ & $0(0)$ & - & $6(66.7)$ & $<0.001$ \\
\hline Vasculitis & $4(1.4)$ & $0(0)$ & $2(1.1)$ & 1.000 & $0(0)$ & \\
\hline Optic nerve atrophy & $3(1.1)$ & $0(0)$ & $0(0)$ & - & $3(33.3)$ & $<0.001$ \\
\hline CME & $2(0.7)$ & $0(0)$ & $2(1.1)$ & 1.000 & $0(0)$ & \\
\hline Secondary retinal detachment & $2(0.7)$ & $0(0)$ & $2(1.1)$ & 1.000 & $0(0)$ & \\
\hline $\begin{array}{l}\text { Peripheral granuloma with } \\
\text { epiretinal membrane }\end{array}$ & $2(0.7)$ & $0(0)$ & $2(1.1)$ & 1.000 & $0(0)$ & \\
\hline Retinal tear & $2(0.7)$ & $0(0)$ & $1(0.5)$ & 1.000 & $0(0)$ & \\
\hline Vitritis & $1(0.4)$ & $0(0)$ & $1(0.5)$ & 1.000 & $0(0)$ & \\
\hline \multicolumn{7}{|l|}{ CME = cystoid macular edema } \\
\hline $\mathrm{CNV}=$ choroidal neovascularization & & & & & & \\
\hline
\end{tabular}

Table 5: Treatment Regimens for Patients with Ocular Toxoplasmosis.

\begin{tabular}{|c|c|c|c|c|}
\hline & \multicolumn{4}{|l|}{ Treatment } \\
\hline & $\begin{array}{l}\text { Pyrimethamin+ Sulfadiazine } \\
\text { + Oral Prednisone N (\%) }\end{array}$ & $\begin{array}{l}\text { Sulfamethoxazole + Oral } \\
\text { Prednisone N (\%) }\end{array}$ & $\begin{array}{l}\text { Azithromycin + Trimethoprim + } \\
\text { Sulfamethoxazole + Oral Prednisone } \\
N(\%)\end{array}$ & $\begin{array}{l}\text { None } \\
N(\%)\end{array}$ \\
\hline Total $(\mathrm{N}=279)$ & $112(40.1)$ & $76(27.2)$ & $45(16.1)$ & $46(16.5)$ \\
\hline \multicolumn{5}{|l|}{ Diagnosis } \\
\hline $\begin{array}{l}\text { Congenital ocular toxoplasmosis ( } \mathrm{n} \\
=5 \text { ) }\end{array}$ & $2(40)$ & $0(0)$ & $0(0)$ & $3(60)$ \\
\hline $\begin{array}{l}\text { Acquired ocular toxoplasmosis } \\
(n=186)\end{array}$ & $71(38.2)$ & $70(37.6)$ & $45(24.2)$ & $0(0)$ \\
\hline $\begin{array}{l}\text { Acquired ocular toxoplasmosis in } \\
\text { HIV patients }(n=9)\end{array}$ & $5(55.6)$ & $4(44.4)$ & $0(0)$ & $0(0)$ \\
\hline Undetermined $(n=79)$ & $34(43.0)$ & $2(2.5)$ & $0(0)$ & $43(54.4)$ \\
\hline
\end{tabular}

Treatment was given for at least 4 weeks, dosages were as follows:

Pyrimethamine: $75-100 \mathrm{mg}$ induction dose for 3 days followed by maintenance dose of $50 \mathrm{mg}$ daily; sulfadiazine $2 \times 1 \mathrm{~g}$ daily; sulfamethoxazole $2 \times 500$ mg daily every 12 hours; azithromycin $1500 \mathrm{mg}$ induction followed by $100 \mathrm{mg}$ maintenance dose; trimethoprim-sulfamethoxazole $2 \times 480 \mathrm{mg}$ daily; prednisone in combination with above regimens: $1 \mathrm{mg} / \mathrm{kg}$ with weekly taper.

with large decreases in visual acuity and neurotoxoplasmosis later developed in one. Neuroretinitis, clinically defined by optic disc edema with hemorrhages and a macular star was noted in three patients. Although usually seen in the setting of cat scratch disease and leptospirosis $[27,28]$, several studies have reported the occurrence in patients with recent serological evidence of toxoplasmosis $[29,30]$. Juxtapapillary choroiditis (Jensen's Disease) was noted in three patients and is characterized by retinochoroiditis adjacent to the optic disc. The edema that surrounds the lesion ultimately involves part of the nerve head, often inducing optic neuritis. Immunocompetent patients generally have a good prognosis with partial recovery of vision, while those who are immunocompromised generally do not [31,32].

Sulfadiazine, pyrimethamine, and systemic corticosteroids continue to be the most commonly used therapy for OT [33]. Although treatment for OT has historically aimed to reduce the duration and severity of intraocular inflammation, a large review of the literature examining the effectiveness of treatment for acute toxoplasmic retinochoroiditis by Stanford et al., found no clear evidence of a beneficial effect of antimicrobial treatment on the 
duration of inflammation in patients [34]. Furthermore, in the largest prospective trial assessing the effectiveness of various treatments for OT, including classical therapy and TMP-SMX, Rothova et al. reported no difference in the duration of inflammatory activity as well as in the mean recurrence rate after three years of follow-up between treated and untreated patients [35]. Since their report, similar findings have been described [33,36,37].

Limitations of our study include the short duration of followup along with the reliance on purely clinical diagnoses, which increases the risk of misclassification of patients. However, the characteristic initial presentation of OT and subsequent clinical response to treatment allowed us to be confident in the diagnoses. Other limitations of this study include having to rely on the accuracy of medical records.

In summary, this present study examines the clinical features of OT in a previously unassessed region. OT continues to be an important medical issue, particularly in younger individuals, who are at an increased risk of infection and recurrence. To our knowledge, this is the first report describing ocular toxoplasmosis in the Cuban population. Identifying and describing these patients will offer further insights into the characterization of ocular toxoplasmosis in the Caribbean and is an important first step in determining toxoplasmosis and uveitis population-based rates of disease in Cuba.

\section{Acknowledgements}

Financial support: The Montefiore Department of Ophthalmology is the recipient of an unrestricted grant from Research to Prevent Blindness. This study was funded in part by Research to Prevent Blindness. The sponsor or funding organization had no role in the design or conduct of this research.

None of the authors of this manuscript, (J. Daniel Diaz, M.D.; Jorge L. Bustillo, MD; Idarmes C. Pacheco MD; David C. Gritz, MD, $\mathrm{MPH})$, have any proprietary interests or conflicts of interest related to this submission.

Data from this manuscript was presented at the ARVO annual meeting taking place in Orlando, Florida, USA on May4-8, 2014. Diaz JD, Bustillo J, Gritz DC. Ocular Toxoplasmosis: Clinical Features in 279 Patients from Central Cuba. Presentation at the Association for Research in Vision and Ophthalmology (ARVO) Annual Meeting, May 4-8, 2014, Orlando, FL.

\section{References}

1. de-la-Torre A, Lopez-Castillo CA, Gomez-Marin JE (2009) Incidence and clinical characteristics in a Colombian cohort of ocular toxoplasmosis. Eye (Lond) 23: 1090-1093.

2. Glasner PD, Silveira C, Kruszon-Moran D, Martins MC, Burnier Júnior M, e al. (1992) An unusually high prevalence of ocular toxoplasmosis in southern Brazil. Am J Ophthalmol 114: 136-144.

3. Khan A, Jordan C, Muccioli C, Vallochi AL, Rizzo LV, et al. (2006) Genetic divergence of Toxoplasma gondii strains associated with ocular toxoplasmosis, Brazil. Emerg Infect Dis 12: 942-949.

4. Holland GN, Buhles WC, Jr., Mastre B, Kaplan HJ (1989) A controlled retrospective study of ganciclovir treatment for cytomegalovirus retinopathy. Use of a standardized system for the assessment of disease outcome. UCLA CMV Retinopathy. Study Group. Arch Ophthalmol 107: 1759-1766.
5. Bosch-Driessen LE, Berendschot TT, Ongkosuwito JV, Rothova A (2002) Ocular toxoplasmosis: clinical features and prognosis of 154 patients. Ophthalmology 109: 869-878.

6. Friedmann CT, Knox DL (1969) Variations in recurrent active toxoplasmic retinochoroiditis. Arch Ophthalmol 81: 481-493.

7. Holland GN, Crespi CM, ten Dam-van Loon N, Charonis AC, Yu F, et al. (2008) Analysis of recurrence patterns associated with toxoplasmic retinochoroiditis. Am J Ophthalmol 145: 1007-1013.

8. Atmaca LS, Simsek T, Batioglu F (2004) Clinical features and prognosis in ocular toxoplasmosis. Jpn J Ophthalmol 48: 386-391.

9. Holland GN (2003) Ocular toxoplasmosis: a global reassessment. Part I: epidemiology and course of disease. Am J Ophthalmol 136: 973-988.

10. Garweg JG, Scherrer JN, Halberstadt M (2008) Recurrence characteristics in European patients with ocular toxoplasmosis. Br J Ophthalmol 92: 12531256.

11. Gilbert RE, Dunn DT, Lightman S, et al. (1999) Incidence of symptomatic toxoplasma eye disease: aetiology and public health implications. Epidemiol Infect 123: 283-289.

12. Bonfioli AA, Orefice F (2005) Toxoplasmosis. Semin Ophthalmol 20: 129141.

13. Burnett AJ, Shortt SG, Isaac-Renton J, King A, Werker D, et al (1998) Multiple cases of acquired toxoplasmosis retinitis presenting in an outbreak. Ophthalmology 105: 1032-1037.

14. Couvreur J, Thulliez P (1996) [Acquired toxoplasmosis of ocular or neurologic site: 49 cases]. Presse Med 25: 438-442.

15. Gilbert RE, Stanford MR (2000) Is ocular toxoplasmosis caused by prenatal or postnatal infection? Br J Ophthalmol 84: 224-226.

16. Holland GN (1999) Reconsidering the pathogenesis of ocular toxoplasmosis Am J Ophthalmol 128: 502-505.

17. Tan HK, Schmidt D, Stanford M, Teär-Fahnehjelm K, Ferret N, et al (2007) Risk of visual impairment in children with congenital toxoplasmic retinochoroiditis. Am J Ophthalmol 144: 648-653.

18. Meenken C, Assies J, van Nieuwenhuizen O, Holwerda-van der Maat WG, van Schooneveld MJ, et al. (1995) Long term ocular and neurological involvement in severe congenital toxoplasmosis. $\mathrm{Br} \mathrm{J}$ Ophthalmol 79: 581584.

19. Kodjikian L, Wallon M, Fleury J, Denis P, Binquet C, et al. (2006) Ocular manifestations in congenital toxoplasmosis. Graefes Arch Clin Exp Ophthalmol 244: 14-21.

20. Garza-Leon M, Garcia LA (2012) Ocular toxoplasmosis: clinical characteristics in pediatric patients. Ocul Immunol Inflamm 20: 130-138.

21. Soares JA, Nasser LS, Carvalho SF, Caldeira AP (2011) [Ocular findings in children with congenital toxoplasmosis]. Arq Bras Oftalmol 74: 255-257.

22. Cochereau-Massin I, LeHoang P, Lautier-Frau M, Zerdoun E, Zazoun L, et al. (1992) Ocular toxoplasmosis in human immunodeficiency virus-infected patients. Am J Ophthalmol 114: 130-135

23. Holland GN (1989) Ocular toxoplasmosis in the immunocompromised host. Int Ophthalmol 13: 399-402.

24. Moorthy RS, Smith RE, Rao NA (1993) Progressive ocular toxoplasmosis in patients with acquired immunodeficiency syndrome. Am J Ophthalmol 115: 742-747.

25. Gagliuso DJ, Teich SA, Friedman AH, Orellana J (1990) Ocular toxoplasmosis in AIDS patients. Trans Am Ophthalmol Soc 88: 63-86.

26. Holland GN, Engstrom RE Jr, Glasgow BJ, Berger BB, Daniels SA, et al. (1988) Ocular toxoplasmosis in patients with the acquired immunodeficiency syndrome. Am J Ophthalmol 106: 653-667.

27. Biancardi AL, Curi AL (2013) Cat-Scratch Disease. Ocul Immunol Inflamm. 
28. Ray S, Gragoudas E (2001) Neuroretinitis. Int Ophthalmol Clin 41: 83-102.

29. Fish RH, Hoskins JC, Kline LB (1993) Toxoplasmosis neuroretinitis Ophthalmology 100: 1177-1182

30. Smith JR, Cunningham ET, Jr (2002) Atypical presentations of ocular toxoplasmosis. Curr Opin Ophthalmol 13: 387-392.

31. Eckert GU, Melamed J, Menegaz B (2007) Optic nerve changes in ocula toxoplasmosis. Eye (Lond) 21: 746-751.

32. Grossniklaus HE, Specht CS, Allaire G, Leavitt JA (1990) Toxoplasma gondii retinochoroiditis and optic neuritis in acquired immune deficiency syndrome. Report of a case. Ophthalmology 97: 1342-1346.

33. Holland GN, Lewis KG (2002) An update on current practices in the management of ocular toxoplasmosis. Am J Ophthalmol 134: 102-114.
34. Stanford MR, See SE, Jones LV, Gilbert RE (2003) Antibiotics for toxoplasmic retinochoroiditis: an evidence-based systematic review. Ophthalmology 110 : 926-931.

35. Rothova A, Meenken C, Buitenhuis HJ, Brinkman CJ, BaarsmaGS et al. (1993) Therapy for ocular toxoplasmosis. Am J Ophthalmol 115: 517-523.

36. Bosch-Driessen LH, Verbraak FD, Suttorp-Schulten MS, et al. (2002) A prospective, randomized trial of pyrimethamine and azithromycin vs pyrimethamine and sulfadiazine for the treatment of ocular toxoplasmosis. Am J Ophthalmol 134: 34-40.

37. Yazici A, Ozdal PC, Taskintuna I, Kavuncu S, Koklu G (2009) Trimethoprim/ Sulfamethoxazole and azithromycin combination therapy for ocular toxoplasmosis. Ocul Immunol Inflamm 17: 289-291.

Copyright: (c) 2016 Diaz JD, et al. This is an open-access article distributed under the terms of the Creative Commons Attribution License, which permits unrestricted use, distribution, and reproduction in any medium, provided the original author and source are credited. 